\title{
Exogenous IL-2 Controls the Balance in Th1, Th17, and Treg Cell Distribution in Patients with Progressive Rheumatoid Arthritis Treated with TNF-Alpha Inhibitors
}

\author{
Agata Kosmaczewska, ${ }^{1,4}$ Lidia Ciszak, ${ }^{1}$ Jerzy Swierkot, ${ }^{2}$ Aleksandra Szteblich, ${ }^{1}$ \\ Katarzyna Kosciow, ${ }^{3}$ and Irena Frydecka ${ }^{1}$
}

Abstract - Interleukin-2 (IL-2) has been suggested to control Treg/Th17 balance. Recently, we reported a relationship of rheumatoid arthritis (RA) activity/progression with irreversible systemic Treg and Th1 defects including serum IL-2 shortage. Herein, we explore the role of in vitro stimulation with rIL-2 in the observed immune alterations reversal. Patients with stable or progressive RA were assigned to methotrexate (MTX) group or to TNF-alpha inhibitors (iTNF) group, respectively. Flow cytometric analyses were performed before and after 6 months of treatment. Circulating Th1, Th17, and Treg cells were determined before and after 72-h culture with anti-CD3 + rIL-2. Before therapy, 72-h stimulation restored recently observed phenotypic Th cell alterations, except for the enriched Th17 subset normalized as late as after therapy in all patients. Under 6-month therapy, anti-CD3 stimulation changed the Th cell distribution only in progressive RA; despite Th1 enrichment, it revealed Treg population defects, which were completely reversed by exogenous IL-2 added to the stimulating culture. Our paper shows that in aggressive RA patients exhibiting serum IL-2 shortage despite iTNF therapy, exogenous rIL-2 is capable of promoting Treg differentiation affected by chronic activation, thus supporting its use in the combined strategy of biologic treatment of the progressive form of RA.

KEY WORDS: rheumatoid arthritis; MTX; iTNF; in vitro stimulation; rIL-2.

\footnotetext{
${ }^{1}$ Department of Immunopathology, Institute of Immunology and Experimental Therapy, Polish Academy of Sciences, R. Weigla St. 12, 53114 Wroclaw, Poland

${ }^{2}$ Department of Rheumatology and Internal Medicine, Wroclaw Medical University, Wroclaw, Poland

${ }^{3}$ Department of Hematology, Regional Hospital, Opole, Poland

${ }^{4}$ To whom correspondence should be addressed at Department of Immunopathology, Institute of Immunology and Experimental Therapy, Polish Academy of Sciences, R. Weigla St. 12, 53-114 Wroclaw, Poland. E-mail: kosmacz@iitd.pan.wroc.pl

Abbreviations: rIL-2, Recombinant interleukin-2; Th, T helper cell; TNF, Tumor necrosis factor; RA, Rheumatoid arthritis; MTX, Methotrexate; PB, Peripheral blood; Treg, Regulatory T cell; IL-6, Interleukin-6; IL-1, Interleukin-1; Foxp3, Forkhead box P3; TGF, Tumor growth factor; IL-17, Interleukin-17; ACR, American College of Rheumatology; VAS, Visual analog scale; DAS28, 28-joint disease activity score; ESR, Erythrocyte sedimentation rate; CRP, C-reactive protein; EULAR, European League Against Rheumatism; NSAID, Non-steroidal anti-inflammatory drug; DMARD, Disease-modifying anti-rheumatic drug; SSZ, Sulfasalazine; PBMC, Peripheral blood mononuclear cell; PMA, Phorbol 12-myristate 23-acetate; IFN, Interferon; BFA, Brefeldin A; BD, Becton Dickinson; PE, Phycoerythrin; FITC, Fluorescein isothiocyanate; $\mathrm{mAb}$, Monoclonal antibody; CTLA-4, Cytotoxic T-lymphocyte antigen-4; PerCP, Peridinin chlorophyll; PFA, Paraformaldehyde; OKT3, Ortho kung T3; TCR, T cell receptor
}

\section{INTRODUCTION}

The development and progression of rheumatoid arthritis (RA) is associated with several alterations in both the proportions of peripheral blood (PB) Th1, Th17, and Treg cells and their counter-regulatory effects [1-3]. A major role in the pathogenesis of RA is attributed to the immune dysregulation depending on the imbalance between antiinflammatory Treg cells and pro-inflammatory Th17 cells $[1,2]$. The effect on Tregs may be a consequence of the inflammatory conditions in the course of RA, suggesting an impact of the cytokine milieu. Tregs in the presence of a pro-inflammatory environment such as TNF-alpha, IL-6, and IL-1-beta become unstable with respect to the affected forkhead box P3 (Foxp3) gene expression and convert to pathogenic Th17 cells, which expand into the sites of inflammation [4]. In addition, serum IL-6 overexpression in RA is capable of conferring on pathogenic Th17 cells resistance to Treg-mediated suppression [5], thus supporting the shift towards inflammatory conditions. 
Th17 and Treg cell distribution and function may also be affected by different types of RA treatments [6-8].

In animal model of autoimmune diseases, such as RA, anti-inflammatory action of Th1 cytokines, including IFNgamma and/or IL-2, has been recently demonstrated [9, 10]. In particular, IL-2 has been suggested to be a cytokine playing a key role in controlling the balance between Treg and Th17 cells in the periphery [10-14]. This Th1 cytokine strongly promotes the differentiation and/or function of Foxp3+ Treg cells, being required for the maintenance of Foxp3 expression by both natural and inducible Tregs [1013]. It is also responsible for Treg cell survival and homeostasis $[14,15]$. Inducible Tregs could differentiate from CD4+CD25- cells in response to IL-2 and TGF-beta [16]. In addition to generation of Tregs, an important aspect of IL-2 function is to constrain IL-17 production by CD4+ T cells, thus inhibiting Th17 polarization [17]. Recently, selective improvement of the levels and function of Tregs has been demonstrated as a result of the low-dose IL-2 immunotherapy in the experimental model of autoimmune disorders [18-23] as well as in the phase I/II clinical trial in patients with type 1 diabetes [24].

In our preliminary data, we reported that the extent of PB Th cell abnormalities and their reversion depended on the duration of the active RA and clearly correlated with progression of the disease [25]. In particular, we found that patients with progressive and, in the most cases, long-term RA remained with quantitative and qualitative Th1 systemic defects as well as a decreased population of functional CTLA-4+ Treg cells in PB despite TNFalpha inhibitor (iTNF) treatment [25]. Herein, we have extended the study and have performed stimulation assays specific for $\mathrm{T}$ cells using anti-CD3 monoclonal antibody to examine the effect of in vitro chronic stimulation through the $\mathrm{T}$ cell receptor/CD3 complex on the proportions of the Th1, Th17, and Treg cell subpopulations before and after 6 months of treatment with MTX and/or iTNF. Based on our recent demonstration of serum IL-2 shortage during RA progression [25], we decided to verify whether the addition of rIL-2 to anti-CD3 stimulating culture could overcome the observed imbalance between anti- and pro-inflammatory helper $\mathrm{T}$ cells. The impact of anti-CD $3 \pm$ rIL-2 stimulation is a novelty in RA patients and has provided much information about the reactivity of their PB CD4 T cells to chronic activation either before or after the therapeutic interventions.

\section{MATERIALS AND METHODS}

\section{Ethics Statement}

The study was approved by the local Ethics Committee at Wroclaw Medical University (Poland). According to the 1964 Declaration of Helsinki and its later amendments, written informed consent was obtained from each patient and healthy donor after a full explanation of the procedure.

\section{Study Populations}

The main characteristics of RA patients and healthy volunteers were shown in Table 1. A total of 36 patients diagnosed with RA based on the 1987 revised classification criteria of the American College of Rheumatology (ACR) [26] and 13 healthy individuals were enrolled in the study. The clinical evaluation of RA was based on the medical history, and number of painful and swollen joints; pain intensity was assessed by the patient on a $100-\mathrm{mm}$ visual analog scale (VAS); 28-joint disease activity score (DAS28) was calculated according to the patient as well as physician and laboratory tests (erythrocyte sedimentation rate (ESR), C-reactive protein (CRP)) at the time when the blood samples were obtained. The clinical and laboratory tests were completed before and after 6 months of the therapy.

All the patients were classified as having active disease if they fulfilled the following criteria: for methotrexate (MTX) treatment, ESR $>30 \mathrm{~mm} / \mathrm{h}$ and/or CRP $>1.5 \mathrm{mg} / \mathrm{dl}$, DAS28 $>3.2$; for treatment with inhibitors of the human tumor necrosis factor alpha (iTNF), ESR $>30 \mathrm{~mm} / \mathrm{h}$ and/or $\mathrm{CRP}>1.5 \mathrm{mg} / \mathrm{dl}$, DAS28 $>5.1$. Also, the parameters allowed determination of the improvement according to the criteria suggested by the European League Against Rheumatism (EULAR) [27]: no response (reduction of DAS28 $<0.6$ ), moderate efficacy of the therapy (reduction of $0.6<$ DAS2 281.2 ), and good efficacy of the therapy (reduction of DAS28 $>1.2$ ). The other accepted inclusion criteria were as follows: age over 18 years, women and men with reproductive potential had to use reliable contraception, the use of non-steroidal anti-inflammatory drugs (NSAIDs) and glucocorticoids in stable doses was allowed. For the iTNF to be used, treatment failure with at least two traditional disease-modifying anti-rheumatic drugs (DMARDs), including MTX, was required. Therefore, iTNF patients enrolled in the study presented clinical and laboratory signs of advanced and progressive disease, including statistically significant differences in regard to active RA duration $(p=0.0000001)$, DAS28 score $(p \leq$ 
Table 1. The Main Characteristics of RA Patients and Healthy Volunteers

\begin{tabular}{|c|c|c|c|c|c|}
\hline \multirow[t]{3}{*}{ Characteristics } & \multicolumn{2}{|l|}{ MTX group } & \multicolumn{2}{|l|}{ iTNF group } & \multirow{3}{*}{$\begin{array}{l}\text { Healthy controls } \\
(n=13)\end{array}$} \\
\hline & \multicolumn{2}{|l|}{$(n=19)$} & \multicolumn{2}{|l|}{$(n=17)$} & \\
\hline & Before & After & Before & After & \\
\hline Age, mean \pm SD (years) & $54.7 \pm 16.4$ & & $50.1 \pm 6.9$ & & $53.5 \pm 9.6$ \\
\hline Sex, female/male & $12 / 7$ & & $14 / 3$ & & $10 / 3$ \\
\hline Duration, mean (range) (months) & $15.2[2.0-79.0]$ & & $123.7[13.0-300.0]$ & & \\
\hline Steroid, $+/-$ & $12 / 7$ & $7 / 12$ & $16 / 1$ & $16 / 1$ & \\
\hline NSAID, $+/-$ & $15 / 4$ & $15 / 4$ & $13 / 4$ & $13 / 4$ & \\
\hline Prior DMARDS, $+/-$ & $10 / 9$ & $10 / 9$ & $16 / 1$ & $16 / 1$ & \\
\hline $\mathrm{DAS} 28$, mean $\pm \mathrm{SD}$ & $5.6 \pm 0.9$ & $3.3 \pm 1.2$ & $6.2 \pm 0.8$ & $4.8 \pm 1.1$ & \\
\hline RF, positive/negative & $16 / 3$ & $16 / 3$ & $13 / 4$ & $13 / 4$ & \\
\hline $\mathrm{CRP}(\mathrm{mg} / \mathrm{l})$ & $24.4 \pm 38.1$ & $10.1 \pm 26.7$ & $24.4 \pm 20.6$ & $19.9 \pm 22.4$ & \\
\hline $\operatorname{ESR}(\mathrm{mm} / \mathrm{h})$ & $31.2 \pm 22.0$ & $18.1 \pm 10.5$ & $29.9 \pm 16.0$ & $27.2 \pm 18.9$ & \\
\hline
\end{tabular}

NSAID non-steroidal anti-inflammatory drugs, DMARDs disease-modifying anti-rheumatic drugs, $D A S 28$ disease activity score rated by the 28 -joint count, $R F$ rheumatoid factor, $C R P$ C-reactive protein, $E S R$ erythrocyte sedimentation rate

0.02), and post-treatment CRP $(p=0.05)$ compared to the MTX group.

In the MTX group, 19 patients with a mean (range) RA duration of 15.2 (2 to 79) months received a stable dose of MTX (10-15 mg once a week orally). If at least moderate improvement was not achieved and there were no significant adverse effects, the dose was up-titrated to a maximum level of $25 \mathrm{mg} /$ week. All MTX patients received 5-15 $\mathrm{mg}$ folic acid 24 to $48 \mathrm{~h}$ after MTX administration.

In the iTNF group with a mean (range) disease duration of 123.7 (13 to 300) months, patients were administered with recommended doses of iTNF: $3 \mathrm{mg} / \mathrm{kg}$ body weight of infliximab, which was given as an intravenous infusion at weeks 0,2 , and 6 and every 8 weeks thereafter (11 patients), subcutaneous injection of adalimumab at $40 \mathrm{mg}$ every other week (two patients), and subcutaneous injection of etanercept at $50 \mathrm{mg}$ every week (four patients). The iTNF patients were allowed to continue treatment with DMARDs; 13 patients with MTX, two patients with sulfasalazine (SSZ), glucocorticoids (prednisone equivalent $10 \mathrm{mg} /$ day), and/or non-steroidal anti-inflammatory drugs, if the treatment regimens were not modified for 4 weeks before the study. The course of the above therapies lasted for at least 6 months.

Among the 19 patients treated with MTX, 14 achieved improvement and 5 a partial response (good and moderate efficacy, respectively). However, among 17 patients who were administered iTNF, 12 achieved improvement, 2 a partial response, and in 3 cases, the treatment was ineffective.
Thirteen healthy controls were free of chronic diseases, including autoimmune, inflammatory, and neoplastic disorders and matched with patients for age and sex with no statistically significant differences in comparison with RA patients.

\section{Cell Preparation}

All blood samples were collected into collection tubes containing $0.2 \mathrm{ml}$ of sodium heparin. Peripheral blood mononuclear cells (PBMCs) were prepared by density gradient centrifugation over Lymphoflot (Biotest, Germany) for further procedures, including stimulation assays and flow cytometric analysis of CD4 $+\mathrm{T}$ cell subsets examined.

\section{Flow Cytometric Analysis of Th1 and Th17 Cells}

Before incubation of the cells with phorbol 12myristate 23-acetate (PMA), CD4+ T cells were purified by negative selection with $\mathrm{CD} 4+\mathrm{T}$ cell isolation kit by magnetic cell sorting (Miltenyi Biotec) to avoid PMAmediated internalization and degradation of the CD4 molecule, which would affect the identification of Th1 (CD4+IL-17-IFN-gamma+) and Th17 (CD4+IFNgamma-IL-17+) cells [28]. Then, the cells were stimulated with $25 \mathrm{ng} / \mathrm{ml} \mathrm{PMA}$ and $1 \mu \mathrm{g} / \mathrm{ml}$ of ionomycin (Ion) (Sigma-Aldrich) in the presence of $10 \mu \mathrm{g} / \mathrm{ml}$ of brefeldin A (BFA, protein transport inhibitor) and cultured for $4 \mathrm{~h}$ at $37^{\circ} \mathrm{C}$ in a humidified $5 \% \mathrm{CO}_{2}$ incubator followed by the cells' fixation and permeabilization with BD 
Permeabilizing Solution 2 (Becton Dickinson) according to the manufacturer's instruction. Next, the cells were stained with phycoerythrin (PE)-labeled anti-human IL17 (eBioscience) and fluorescein isothiocyanate (FITC)labeled anti-human IFN- $\gamma$ (Becton Dickinson) monoclonal antibodies (mAbs).

\section{Flow Cytometric Analysis of Treg and Functional CTLA-4+ Treg Subpopulations}

Regulatory $\mathrm{T}$ cell subsets were defined as CD4+CD25 ${ }^{\text {high }}$ FoxP3+ and CD4+FoxP3+CTLA-4+ cells. Directly after isolation, PBMCs were first aliquoted into tubes without PMA+ion stimulation, and then surface-stained with PerCP anti-human CD4 and FITC anti-human CD25 or FITC anti-human CTLA-4 mAbs. After fixation with $2 \%$ PFA and permeabilization with BD Permeabilizing Solution 2 (Becton Dickinson), the cells were incubated with PE anti-human FoxP3 mAb.

After staining, the cells were washed and immediately analyzed with a FACScan cytometer equipped with Cell Quest software (BD Bioscience Pharmingen). In each case, staining was compared with that of the appropriately labeled isotype control. Lymphocytes were gated on the basis of forward- and side-scatter properties, and at least $30,000 \mathrm{CD} 4+\mathrm{T}$ cells were analyzed.

\section{Activation of Human T Cells In Vitro}

To determine the effect of in vitro stimulation on the populations studied, PBMCs were resuspended to $1 \times 10^{6}$ cells/ml in RPMI 1640 medium (Gibco, Paisley, UK) supplemented with $10 \%$ fetal calf serum (Flow Labs, UK), L-glutamine, and $50 \mu \mathrm{g} / \mathrm{ml}$ gentamycin (Gibco), and cultured with $10 \mathrm{ng} / \mathrm{ml}$ of anti-CD3 mAb OKT3 (Ortho, Neckargemund, Germany) in the presence or absence of $500 \mathrm{U} / \mathrm{ml}$ of rIL-2 (Eurocetus, Amsterdam, The Netherlands) with subsequent labelling as described above. Control cultures without stimulants were included in each experiment. The cultures were incubated at $37{ }^{\circ} \mathrm{C}$ in a humidified atmosphere containing $5 \% \mathrm{CO}_{2}$ for $72 \mathrm{~h}$.

\section{Statistical Analyses}

One-way ANOVA test was used to determine significant differences between groups. Paired data were compared by the Wilcoxon signed rank test. Results were considered statistically significant when $p \leq 0.05$. Data were presented as the mean \pm SD. STATISTICA 5.5 (edited in 1999) was used in the statistical calculations.

\section{RESULTS}

\section{Pre-treatment Distribution of Th1, Th17, and Treg Cells in the Peripheral Blood}

We confirm our recent observation that circulating Th1 cell population was significantly lower in the progressive RA patients compared to the MTX group and controls (Fig. 1a) [24]. PB Th17 populations in both groups of patients were similar and significantly higher than in healthy subjects (Fig. 1b). Compared to controls, Treg cells in patients before iTNF treatment were downregulated, whereas in the MTX group, they reached similar levels (Fig. 1c). Also, circulating CTLA-4+ Treg population in the most advanced RA patients was markedly lower compared to controls (Fig. 1d).

\section{The Influence of 72-h Culture with Anti-CD3 \pm rIL-2 on the Proportions of Th1, Th17, and Treg Cells in RA Patients Before Therapeutics Administration}

Anti-CD3 stimulation resulted in a decrease of the Th1 subpopulation in the non-aggressive RA patients (MTX group) and controls, whereas in the iTNF group, the Th1 cell proportion was unchanged. Co-stimulation with rIL-2 did not influence the Th1 subset in patients; in contrast, a marked Th1 decrease was observed in controls. We did not find any differences in the percentages of Th1 cells between studied groups in both culture conditions (Fig. 1a).

We observed that stimulation with anti-CD3 mAb led to no obvious changes in the percentages of Th17 cells in the studied groups. Recombinant IL-2 co-stimulation diminished the Th17 population in controls, only; hence, the Th17 subset remained enriched in all patients at each stimulation condition (Fig. 1b).

Also, anti-CD3 stimulation resulted in no Treg changes in all groups. In contrast, stimulation with anti-CD3+ rIL-2 markedly increased Treg values in all individuals. Considering both stimulating conditions, there were no differences in proportions of Tregs between studied groups (Fig. 1c).

Fig. 1. The effect of in vitro stimulation with anti-CD3 and anti-CD3+ rIL-2 on helper T cell subpopulations from RA patients before (left panel) and after (right panel) 6 months of the therapy with MTX and/or iTNF. Results are shown as the mean percentage (mean $\pm \mathrm{SD})$ of a Th1 (CD4+ IL-17-IFN-gamma+) T cells, b Th17 (CD4+IFN-gamma-IL-17+) T cells, c Treg $(\mathrm{CD} 4+\mathrm{CD} 25++$ Foxp3+) cells, and $\mathbf{d}$ functional Treg (CD4+ Foxp3+CTLA-4+) cells. Markers are as follows: ${ }^{\dagger} 0.05<P \leq 0.08, * 0.001$ $<P \leq 0.05, * * 0.0001<P \leq 0.001$, and $* * * P \leq 0.0001$. 
$\mathbf{a}$

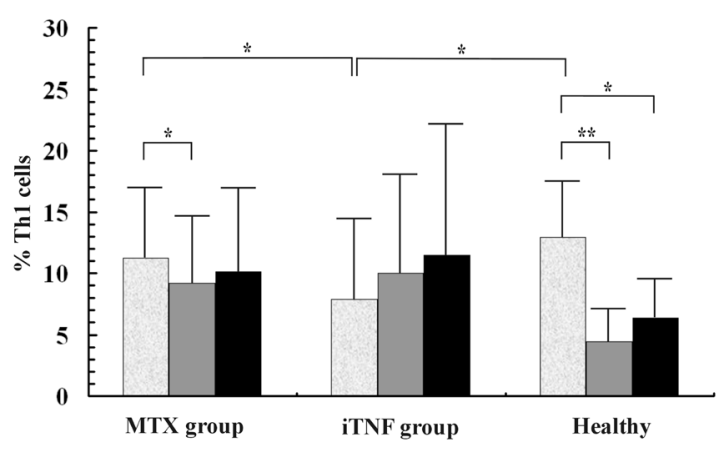

b

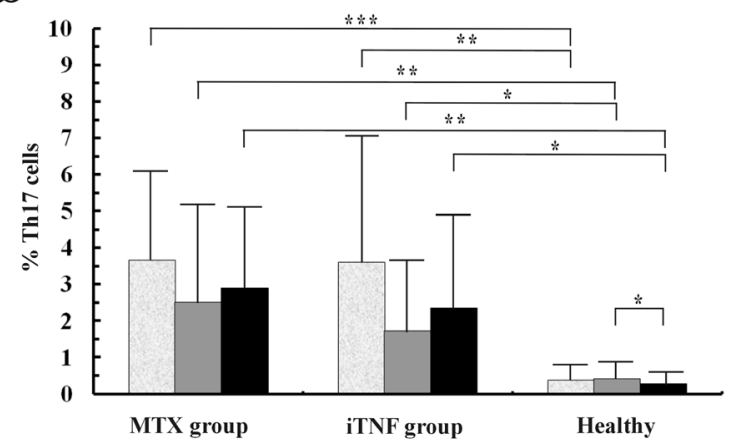

c

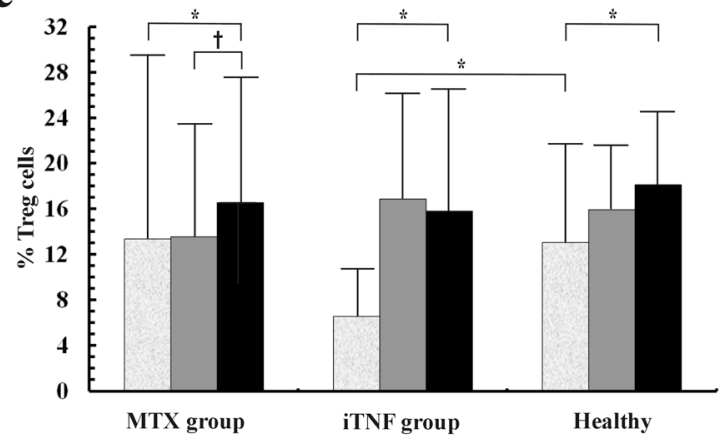

d

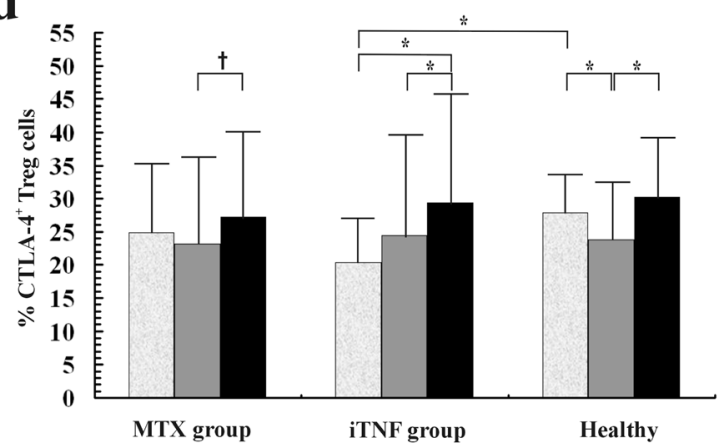

AFTER THERAPY
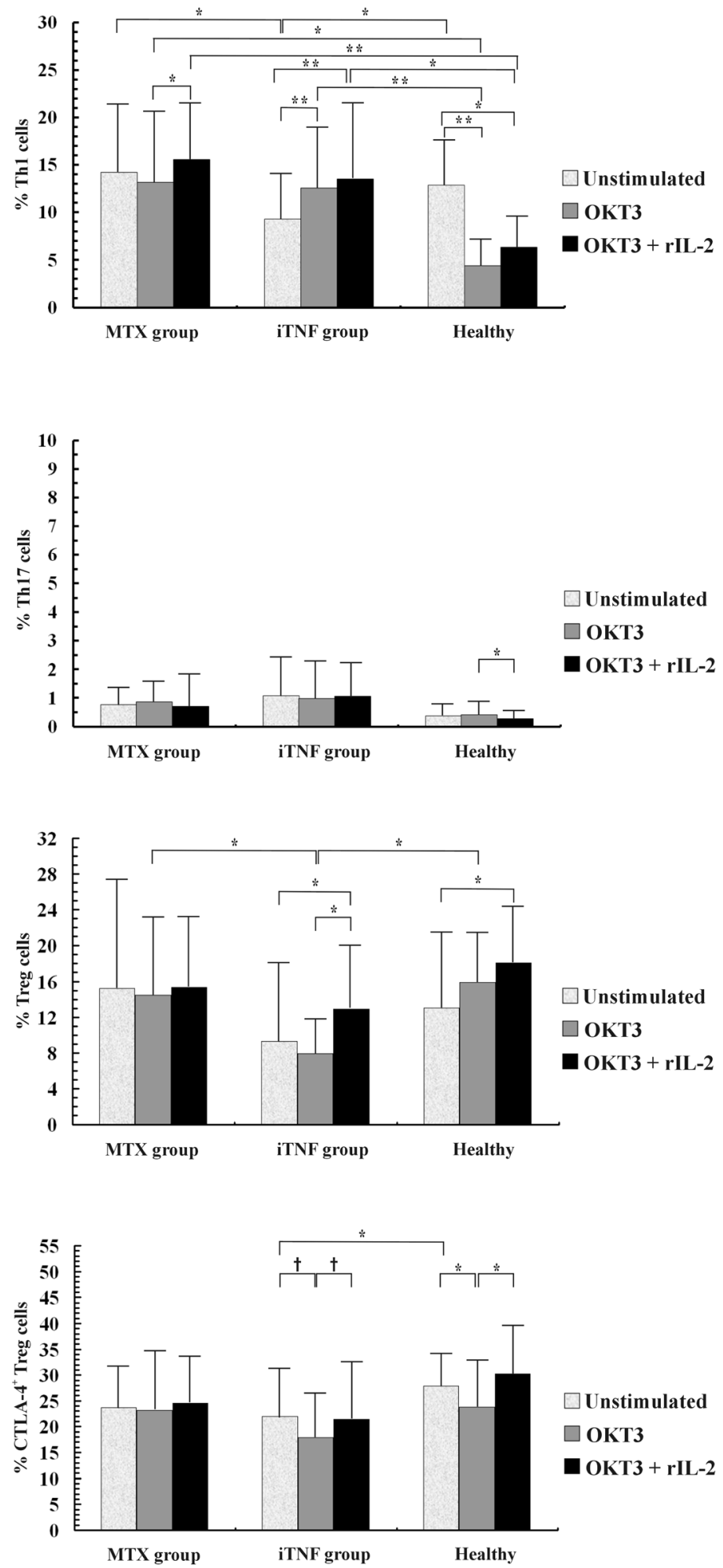
Stimulation with anti-CD3 mAb resulted in a significant decrease of the proportions of CTLA-4+ Treg cells only in controls, whereas there were no changes in RA patients. Co-stimulation with rIL-2 led to increase of the proportions of functional Tregs in progressive RA patients and controls; in MTX patients, its increase was of borderline significance compared to anti-CD3-stimulated cells. In both culture conditions, CTLA-4+ Tregs from all individuals reached similar values (Fig. 1d).

\section{Post-treatment Distribution of Th1, Th17, and Treg Cells in the Peripheral Blood}

We observed no impact of the treatment with MTX and/or iTNF on circulating Th1 cells; hence, the Th1 population remained defective in the iTNF group compared to others (Fig. 1a). We observed a post-treatment decrease of the PB Th17 cell population to normal levels in both groups of patients (Fig. 1b). After iTNF therapy, there was a slight increase of the PB Treg population to a normal level; therefore, no obvious differences in the proportions of PB Treg cells between studied groups were found (Fig. 1c). The treatment did not change the CTLA-4+ Treg subset in all patients; thus, we still observed defective proportions of these functional Tregs in the iTNF patients compared to controls (Fig. 1d).

\section{The Influence of 72-h Culture with Anti-CD3 \pm rIL-2 on the Proportions of Th1, Th17, and Treg Cells in RA Patients After 6 Months of Therapy}

Anti-CD3 stimulation resulted in no Th1 cell population changes in the MTX group, its increase in iTNF patients, and a decrease in controls. In all RA patients, the anti-CD3-stimulated Th1 cell population was enriched compared to controls. Co-stimulation with rIL-2 significantly increased the Th1 subset in all RA patients. In contrast, in controls, the addition of rIL-2 led to a decline in the Th1 population. In consequence, the proportions of Th1 cells co-stimulated with rIL-2 in all RA patients were markedly higher than in controls (Fig. 1a).

Also, we found no influence of anti-CD3 as well as anti-CD3+rIL-2 stimulation on the Th17 population in RA. Co-stimulation with rIL-2 diminished the Th17 subset in controls, only; nevertheless, the in vitro stimulated Th17 cell values were comparable in all subjects (Fig. 1b).

Anti-CD3 stimulation did not significantly change the Treg cell population in all individuals; however, a nonsignificant decrease, revealing a marked Treg defect, was noted in the iTNF group, only. Co-stimulation with rIL-2 resulted in an increase of the Treg population in the iTNF group as well as in controls; thus, co-stimulated Treg values in patients reached a normal level (Figs. 1c and 2a).

We did not find any changes in the percentages of anti-CD3-stimulated CTLA-4+ Tregs in the MTX group. In controls and in the iTNF group, stimulation with antiCD3 alone diminished the CTLA-4+ Treg population, which reached normal values after co-stimulation with rIL-2. Therefore, the CTLA-4+ Treg proportions after anti-CD3+rIL-2 stimulation were similar in all individuals studied (Figs. 1d and 2b).

\section{DISCUSSION}

In the present paper, we report that chronic anti-CD3 stimulation possess a normalizing effect on CD4 $\mathrm{T}$ cell subpopulations by overcoming Th1 and Treg cell defects seen mainly in progressive disease [25]. With this respect, our finding contradicts the previous demonstration of impaired Th1 responses following stimulation with immobilized OKT3 in RA [29], which may result from substantial differences in the experimental procedures. The mechanisms leading to the partial restoration of both the anti-inflammatory subpopulations under stimulating conditions in advanced RA are not clear. The possibility that Th1 downregulation may become reversible due to the withdrawal from the culture of PB factors which are capable of affecting the Th1 population, such as MTX or statins, cannot be neglected [30, 31]. Moreover, under in vitro conditions, selective migration of Th1 cells into the sites of inflammation normally observed in active RA is avoided [32-34]. Therefore, when activated through TCR/ CD3, Th1 cells could expand to the normal levels and secrete suitable amounts of IL-2, playing a major role in the generation, survival, and function of Treg cells [10, 13, $17,35,36]$. In contrast, in untreated patients with nonaggressive RA, anti-CD3 stimulation diminished the Th1 population similarly to the control group, probably due to proper inhibitory function of Tregs and higher consumption of endogenous IL-2 by these cells.

We observed that the only population remaining intact after anti-CD3 \pm IL-2 stimulation in untreated RA was Th17, its proportion being similarly expanded in all patients. This effect could be attributed to Th17 resistance to the suppressive function of Tregs and is in agreement with other studies [37-39]. The lack of Th17 normalization might contribute to the maintenance of the inflammation despite reversal of other Th cell populations under stimulating conditions. An unexpected observation, however, was the lack of inhibitory effect of exogenous IL-2 on 
Unstimulated

a
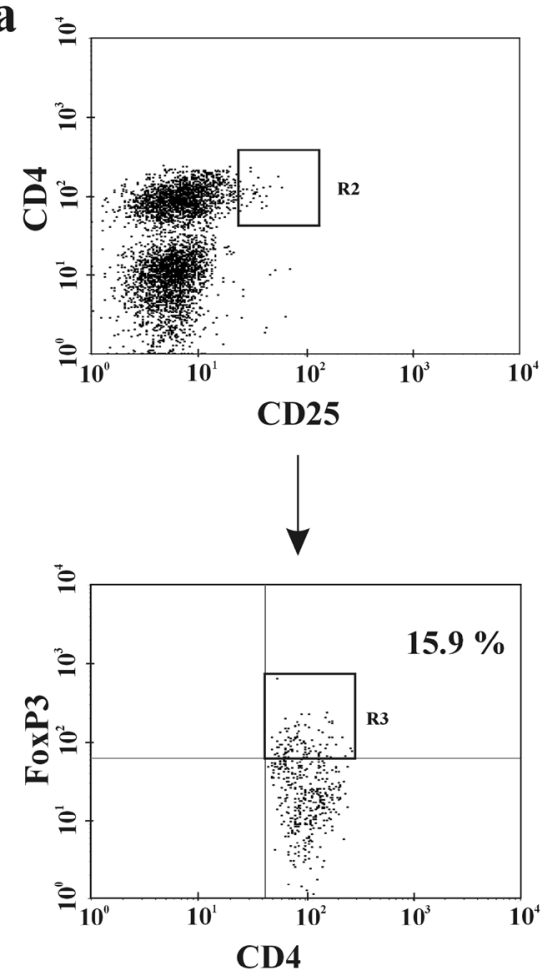

b

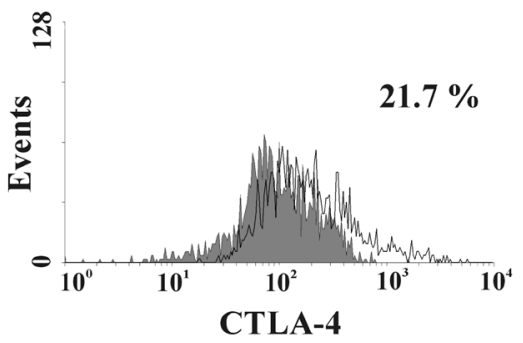

OKT3
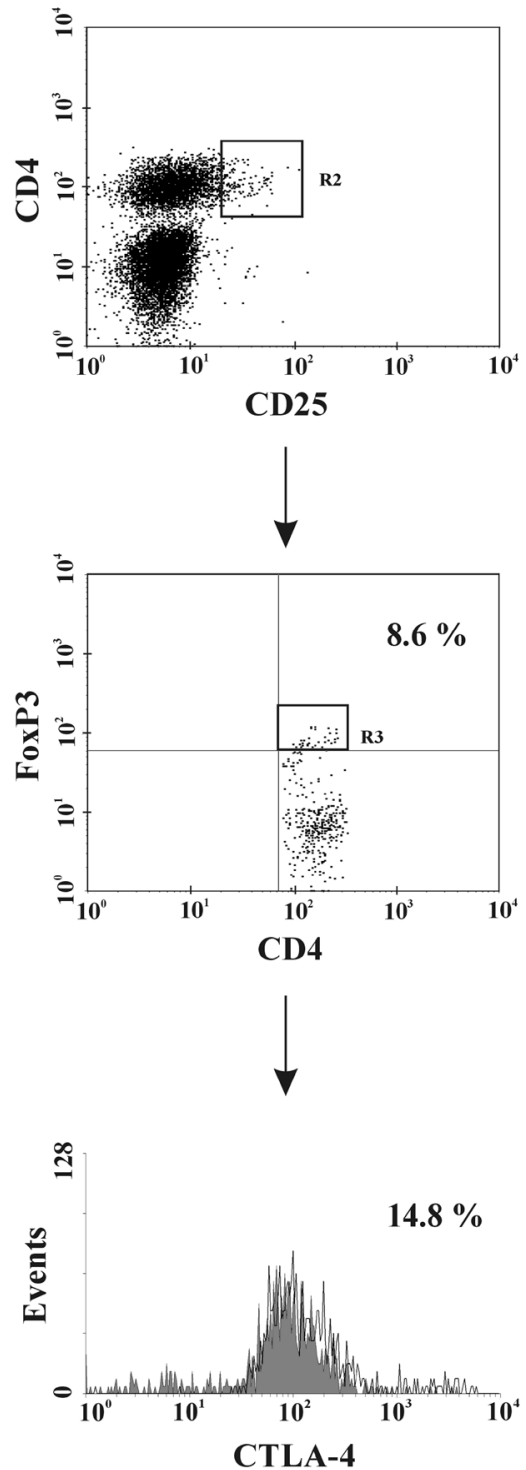

OKT3+rIL-2
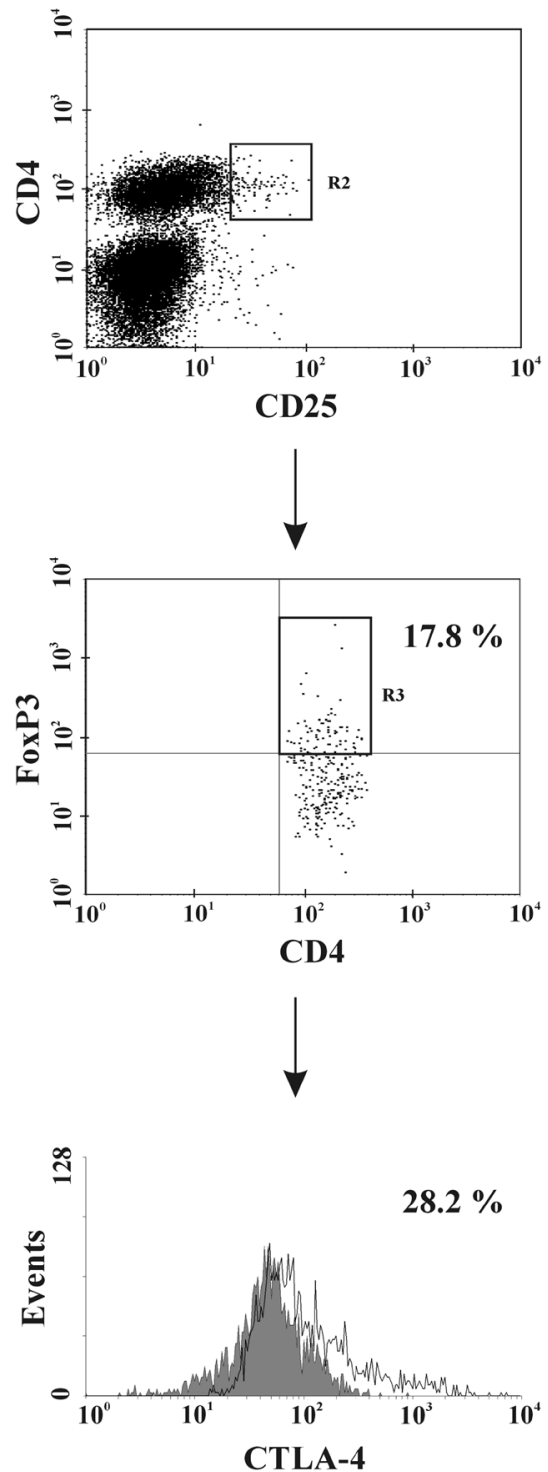

Fig. 2. Exogenous IL-2 corrects a defect in the proportion of Treg and CTLA-4+ Treg cells associated with chronic stimulation in progressive RA patients with ongoing iTNF treatment. One representative example of the expression of a FoxP3 transcription factor in total CD4+CD25++ T cells (Tregs) as well as the expression of b CTLA-4 molecule in Treg cell population (functional Tregs) before (left panel) and after 72-h stimulation with anti-CD3 mAb alone (medium panel) and with addition of exogenous IL-2 (right panel).

Th17 differentiation in active disease, which just apparently contradicted previous reports $[17,38]$. It is likely that in vitro activated PBMCs from patients could secrete into the culture abundant amounts of IL-1, exhibiting opposite and decisive effects on Th17 polarization compared to IL-2 $[40,41]$. This finding seems to rule out the clinical relevance of IL-2 supplementation until Th17 normalization. In fact, the reversion of Th17 cell expansion in all RA patients was the main immune advantage of the therapy irrespectively of the therapeutics used. Although the iTNF therapy of the most advanced RA partially corrected also the proportion of Tregs, consistently with our and other reports [7, 25], their qualitative impairment and Th1 systemic defects were still maintained.

In the current study, we demonstrate that therapeutic interventions in RA could change, in addition, the 
reactivity of $\mathrm{CD} 4+\mathrm{T}$ cells to stimulation in the disease severity-dependent manner. In particular, we observed that the population of Th1 cells from progressive patients responded to anti-CD3 stimulation more vigorously, which was consistent with the finding of Th1 hyporesponsiveness reversion after iTNF administration [29]. Furthermore, in vitro activated Th17 cells remained normal in all patients under the treatment, thus suggesting the long-lasting inhibitory effect of the therapeutics used. The only distinction concerned the Treg cell population from patients with advanced disease, where anti-CD3 stimulation resulted in a marked decrement of Treg population, confronting the lack of such response in both the non-aggressive MTX-treated group and controls. The mechanism underlying the observed downregulatory effect of stimulating conditions on Tregs in the iTNF-treated progressive RA patients is not clear. However, it suggests similarity to the acute responses to the infection agents associated with a limited amount of available IL-2 [42, 43]. The infection-induced Treg cell deficiency found in those studies was essential for the initiation of potent Th1 protective responses in the chronic disease [42, 43]. It cannot be excluded that iTNF administration in the most advanced RA contributes to the development of such a compensating mechanism that includes downregulation of the Treg population. At this stage of the study, it is uncertain whether the activation-induced loss of Tregs in progressive patients is only transient or remains long-lasting, but it should be noted that it might promote the restoration of the anti-inflammatory Th1 population. In fact, when the influence of antiCD3 stimulation on Th1 cell values was analyzed, a significant impact was found just after the biologic therapy.

When the influence of exogenous IL-2 on the selected $\mathrm{CD} 4+\mathrm{T}$ cell subsets among the patients under the treatment was analyzed, no significant impact in the MTX group was demonstrated, probably due to the fact that patients with stable RA entered the treatment with no PB Th1 defects. It should be stressed, however, that only in the progressive and iTNF-treated patients, the same who exhibited irreversible systemic loss of IL-2 [25], did supplementation of the culture with this cytokine correct the Treg cell population, which confirms its dependence on the sufficient amounts of IL-2 in the microenvironment. Resistance of IL-2-induced Treg cells to Th17 conversion by IL-6 abundantly concentrated in patients' sera even after the iTNF administration was demonstrated as well $[25,44]$. Recent studies have linked defects in Tregs found both in mouse and human autoimmune disorders to reduced availability of IL-2 [18, 45-48]. As such, IL-2 seems to be a protective rather than pro-inflammatory cytokine that could be involved in the downregulation of chronic inflammation related to RA progression by shifting the balance from Th17-mediated inflammatory conditions to a Tregmediated tolerant state. Such a normalizing IL-2 potential for effector and regulatory $\mathrm{T}$ cell distribution has already been described in the tumor and the infection microenvironment [19-22, 42, 49-57]. In particular, IL-2 administered at low doses to mice [18-22] and humans [53-57] increased the levels of circulating Tregs, improved their regulatory activity, and protected against chronic inflammation, contrasting with the lack of such responses in effector T cells. Our reports confirms that the Treg population rather than effector T cell subset is dependent on IL-2 availability and points to the possibility that low-dose IL-2 immunotherapy may provide a mechanism for recovering the selective expansion of Tregs for the suppression of autoimmune disorders, especially those ongoing with IL2 systemic deficit. However, the overall reasoning in RA has to be cautious due to the lack of other data on that subject.

In conclusion, our study revealed for the first time that progression of RA is associated with altered responses of Th1, Th17, and Treg cells to stimulation through TCR/ CD3. Addition of exogenous IL-2 to the stimulating culture in untreated patients has no considerable impact on the biology of the populations examined. However, in progressive RA patients still lacking IL-2 despite iTNF treatment, it contributes to maintaining a balance between Treg and effector $\mathrm{T}$ cells required for the immune control of disease progression. Therefore, our study indicates that exogenous IL-2 may be of potential clinical relevance in the most advanced RA. Further studies on the impact of chronic stimulation with addition of rIL-2 need to be performed to ascertain its usefulness in the treatment of the progressive form of this disease.

\section{ACKNOWLEDGMENTS}

This work was supported by a grant from the National Science Centre (Poland): grant no. N N402 244935.

Open Access This article is distributed under the terms of the Creative Commons Attribution License which permits any use, distribution, and reproduction in any medium, provided the original author(s) and the source are credited. 


\section{REFERENCES}

1. Niu, Q., B. Cai, Z.C. Huang, Y.Y. Shi, and L.L. Wang. 2012. Disturbed Th17/Treg balance in patients with rheumatoid arthritis. Rheumatology International 32: 2731-2736.

2. Wang, W., S. Shao, Z. Jiao, M. Guo, H. Xu, and S. Wang. 2012. The Th17/Treg imbalance and cytokine environment in peripheral blood of patients with rheumatoid arthritis. Rheumatology International 32: $887-893$.

3. Harrington, L.E., R.D. Hatton, P.R. Mangan, H. Turner, T.L. Murphy, and K.M. Murphy. 2005. Interleukin-17-producing CD4+ effector T cells develop via a lineage distinct from the Thelper type 1 and 2 lineages. Nature Immunology 6: 1123-1132.

4. Beriou, G., C.M. Costantino, C.W. Ashley, L. Yang, V.K. Kuchroo, C. Baecher-Allan, and D.A. Hafler. IL-17-producing human peripheral regulatory T cells retain suppressive function. Blood 113: 4240-4249.

5. Yang, X.O., R. Nurieva, G.J. Martinez, H.S. Kang, Y. Chung, B.P. Pappu, B. Shah, S.H. Chang, K.S. Schluns, S.S. Watowich, X.H. Feng, A.M. Jetten, and C. Dong. 2008. Molecular antagonism and plasticity of regulatory and inflammatory T cell programs. Immunity 29: 44-56.

6. Ehrenstein, M.R., J.G. Evans, A. Singh, S. Moore, G. Warnes, D.A. Isenberg, and C. Mauri. 2004. Compromised function of regulatory $\mathrm{T}$ cells in rheumatoid arthritis and reversal by anti-TNF-alpha therapy. Journal of Experimental Medicine 200: 277-285.

7. Lina, C., W. Conghua, L. Nan, and Z. Ping. 2011. Combined treatment of etanercept and MTX reverses Th1/Th2, Th17/Treg imbalance in patients with rheumatoid arthritis. Journal of Clinical Immunology 31: 596-605.

8. Samson, M., S. Audia, N. Janikashvili, M. Ciudad, M. Trad, J. Fraszczak, P. Ometti, J.F. Maillefert, P. Miossec, and B. Bonnotte. 2012. Inhibition of IL-6 function corrects Th17/Treg imbalance in rheumatoid arthritis patients. Arthritis \& Rheumatism 64: 2499-2503.

9. Kelchtermans, H., B. De Klerck, T. Mitera, M. Van Balen, D. Bullens, A. Billiau, G. Leclercq, and P. Matthys. 2005. Defective CD4+CD25+ regulatory $\mathrm{T}$ cell functioning in collagen-induced arthritis: an important factor in pathogenesis, counter-regulated by endogenous IFNgamma. Arthritis Research \& Therapy 7: R402-R415.

10. Setoguchi, R., S. Hori, T. Takahashi, and S. Sakaguchi. 2005. Homeostatic maintenance of natural Foxp3+CD25+CD4+ regulatory T cells by interleukin (IL)-2 and induction of autoimmune disease by IL-2 neutralization. Journal of Experimental Medicine 201: 723735 .

11. Fontenot, J.D., J.P. Rasmussen, M.A. Gavin, and A.Y. Rudensky. 2005. A function for interleukin 2 in Foxp3-expressing regulatory $\mathrm{T}$ cells. Nature Immunology 6: 1142-1151.

12. Li, M.O., Y.Y. Wan, S. Sanjabi, A.K. Robertson, and R.A. Flavell. 2006. Transforming growth factor-beta regulation of immune responses. Annual Review of Immunology 24: 99-146.

13. de la Rosa, M., S. Rutz, H. Dorninger, and A. Scheffold. 2004. Interleukin-2 is essential for CD4+CD25+ regulatory T cell function. European Journal of Immunology 34: 2480-2488.

14. Fainboim, L., and L. Arruvito. 2011. Mechanisms involved in the expansion of Tregs during pregnancy: role of IL-2/STAT5 signalling. Journal of Reproductive Immunology 88: 93-98.

15. Zheng, S.G., J. Wang, P. Wang, J.D. Gray, and D.A. Horwitz. 2007. IL-2 is essential for TGF-beta to convert naïve CD4+CD25- cells to CD25+Foxp3+ regulatory T cells and for expansion of these cells. Journal of Immunology 178: 2018-2027.

16. Bluestone, J.A., and A.K. Abbas. 2003. Natural versus adaptive regulatory T cells. Nature Reviews Immunology 3: 253-257.

17. Laurence, A., C.M. Tato, T.S. Davidson, Y. Kanno, Z. Chen, Z. Yao, R.B. Blank, F. Meylan, R. Siegel, L. Hennighausen, E.M. Shevach, and J.J. O'shea. 2007. Interleukin-2 signaling via STAT5 constrains T helper 17 cell generation. Immunity 26: 371-381.
18. Sgouroudis, E., M. Kornete, and C.A. Piccirillo. 2011. IL-2 production by dendritic cells promotes Foxp3+ regulatory T-cell expansion in autoimmune resistant NOD congenic mice. Autoimmunity 44: 406-414.

19. Zhang, H., K.S. Chua, M. Guimond, V. Kapoor, M.V. Brown, T.A. Fleisher, L.M. Long, D. Bernstein, B.J. Hill, D.C. Douek, J.A. Berzofsky, C.S. Carter, E.J. Read, L.J. Helman, and C.L. Mackall. 2005. Lymphopenia and interleukin-2 therapy alter homeostasis of CD4+CD25+ regulatory T cells. Nature Medicine 11: 12381243.

20. Webster, K.E., S. Walters, R. Kohler, T. Mrkvan, O. Boyman, C.D. Surh, S.T. Grey, and J. Sprent. 2009. In vivo expansion of Treg cells with IL-2 mAb complexes; induction of resistance to EAE and longterm acceptance of islet allografts without immunosuppression. Journal of Experimental Medicine 206: 751-760.

21. Wilson, M.S., J.T. Pesce, T.R. Ramalingam, R.W. Thompson, A. Cheever, and T.A. Wynn. 2008. Suppression of murine allergic airway disease by IL-2; anti-IL-2 monoclonal antibody-induced regulatory T cells. Journal of Immunology 181: 6942-6954.

22. Grinberg-Bleyer, Y., A. Baeyens, S. You, R. Elhage, G. Fourcade, S. Gregoire, N. Cagnard, W. Carpentier, Q. Tang, J. Bluestone, L. Chatenoud, D. Klatzmann, B.L. Salomon, and E. Piaggio. 2010. IL-2 reverses established type 1 diabetes in NOD mice by a local effect on pancreatic regulatory T cells. Journal of Experimental Medicine 207: 1871-1878.

23. Brandenburg, S., T. Takahashi, M. de la Rosa, M. Janke, G. Karsten, T. Muzzulini, Z. Orinska, S. Bulfone-Paus, and A. Scheffold. 2008. IL-2 induces in vivo suppression by CD4+CD25+Foxp3+ regulatory T cells. European Journal of Immunology 38: 1643-1653.

24. Hartemann, A., G. Bensimon, C.A. Payan, S. Jacqueminet, O. Bourron, N. Nicolas, M. Fonfrede, M. Rosenzwajg, C. Bernard, and D. Kaltzmann. 2013. Low-dose interleukin 2 in patients with type 1 diabetes: a phase $1 / 2$ randomised, double-blind, placebocontrolled trial. Lancet Diabetes \& Endocrinology 1: 295-305.

25. Kosmaczewska, A., J. Swierkot, L. Ciszak, A. Szteblich, A. Chrobak, L. Karabon, A. Partyka, J. Szechinski, P. Wiland, and I. Frydecka. 2014. Patients with the most advanced rheumatoid arthritis remain with Th1 systemic defects after TNF inhibitors treatment. Rheumatology International 34: 243-253.

26. Arnett, F.C., S.M. Edworthy, D.A. Bloch, D.J. McShane, J.F. Fries, N.S. Cooper, L.A. Healey, S.R. Kaplan, M.H. Liang, H.S. Luthra, et al. 1988. The American Rheumatism Association 1987 revised criteria for the classification of rheumatoid arthritis. Arthritis \& Rheumatism 31: 315-324.

27. Smolen, J.S., R. Landewe, F.C. Breedveld, M. Dougados, P. Emery, C. Gaujoux-Viala, S. Gorter, R. Knevel, J. Nam, M. Schoels, et al. 2010. EULAR recommendations for the management of rheumatoid arthritis with synthetic and biological disease-modifying antirheumatic drugs. Annals of the Rheumatic Diseases 69: 964-975.

28. Hennessy, B., J. North, A. Deru, N. Llewellyn-Smith, and M.W. Lowdell. 2001. Use of Leu3a/3b for the accurate determination of CD4 subsets for measurement of intracellular cytokines. Cytometry 44: $148-152$.

29. Cope, A.P., M. Londei, N.R. Chu, S.B. Cohen, M.J. Elliott, F.M. Brennan, R.N. Maini, and M. Feldmann. 1994. Chronic exposure to tumor necrosis factor (TNF) in vitro impairs the activation of T cells through the $\mathrm{T}$ cell receptor/CD3 complex; reversal in vivo by antiTNF antibodies in patients with rheumatoid arthritis. Journal of Clinical Investigation 94: 749-760.

30. Xinqiang, S., L. Fei, L. Nan, L. Yuan, Y. Fang, X. Hong, T. Lixin, L. Juan, Z. Xiao, S. Yuying, and X. Yongzhi. 2010. Therapeutic efficacy of experimental rheumatoid arthritis with low-dose methotrexate by increasing partially $\mathrm{CD} 4+\mathrm{CD} 25+$ Treg cells and inducing Th1 to Th2 shift in both cells and cytokines. Biomedicine \& Pharmacotherapy 64: $463-471$. 
31. Blaschke, S., V. Viereck, G. Schwarz, H.M. Klinger, S. Guerluek, and G.A. Müller. 2009. Anti-inflammatory effects of atorvastatin on peripheral blood mononuclear cells and synovial fibroblasts in rheumatoid arthritis. Scandinavian Journal of Rheumatology 38: 235-239.

32. Kawashima, M., and P. Miossec. 2005. mRNA quantification of T-bet, GATA-3, IFN-gamma, and IL-4 shows a defective Th1 immune response in the peripheral blood from rheumatoid arthritis patients: link with disease activity. Journal of Clinical Immunology 25: 209-214.

33. van der Graaff, W.L., A.P.A. Prins, T.M.H. Niers, B.A. Dijkmans, and R.A. van Lier. 1999. Quantification of interferon gamma- and interleukin-4-producing T cells in synovial fluid and peripheral blood of arthritis patients. Rheumatology 38: 214-220.

34. Yamada, H., Y. Nakashima, K. Okazaki, T. Mawatari, J.I. Fukushi, N. Kaibara, A. Hori, Y. Iwamoto, and Y. Yoshikai. 2008. Th1 but not Th17 cells predominate in the joints of patients with rheumatoid arthritis. Annals of the Rheumatic Diseases 67: 1299-1304.

35. Thornton, A.M., E.E. Donovan, C.A. Piccirillo, and E.M. Shevach. 2004. IL-2 is critically required for the in vitro activation of CD4+CD256+ T cell suppressor function. Journal of Immunology 172: 6519-6523.

36. Flores Borja, F., E.C. Jury, C. Mauri, and M.R. Ehrenstein. 2008. Defects in CTLA-4 are associated with abnormal regulatory $\mathrm{T}$ cell function in rheumatoid arthritis. Proceedings of the National Academy of Sciences USA 105: 19396-19401.

37. Stummvoll, G.H., R.J. DiPaolo, E.N. Huter, T.S. Davidson, D. Glass, J.M. Ward, and E.M. Shevach. 2008. Th1, Th2, and Th17 effector T cell-induced autoimmune gastritis differs in pathological pattern and in susceptibility to suppression by regulatory T cells. Journal of Immunology 181: 1908-1916.

38. Chauhan, S.K., J. El Annan, T. Ecoiffier, S. Goyal, Q. Zhang, D.R. Saban, and R. Dana. 2009. Autoimmunity in dry eye is due to resistance of Th17 to Treg suppression. Journal of Immunology 182: $1247-1252$.

39. Vercoulen, Y., E.J. Wehrens, N.H. van Teijlingen, W. de Jager, J.M. Beekman, and B.J. Prakken. 2009. Human regulatory T cell suppressive function is independent of apoptosis induction in activated effector T cells. PLoS ONE 4: e7183.

40. Kryczek, I., S. Wei, L. Vatan, J. Escara-Wilke, W. Szeliga, E.T. Keller, and W. Zou. 2007. Opposite effects of IL-1 and IL-2 on the regulation of IL-17+ T cell pool. IL-1 subverts IL-2-mediated suppression. Journal of Immunology 179: 1423-1426.

41. Matsuyama, Y., H. Okazaki, M. Hoshino, S. Onishi, Y. Kamata, K. Nagatani, T. Nagashima, M. Iwamoto, T. Yoshio, H. Ohto-Ozaki, H. Tamemoto, M. Komine, H. Sekiya, S. Tominaga, and S. Minota. 2012. Sustained elevation of interleukin-33 in sera and synovial fluids from patients with rheumatoid arthritis non-responsive to anti-tumor necrosis factor: possible association with persistent IL1 beta signaling and a poor clinical response. Rheumatology International 32: 1397-1401.

42. Benson, A., S. Murray, P. Divakar, N. Burnaevskiy, R. Pifer, J. Forman, and F. Yarovinsky. 2012. Microbial infection-induced expansion of effector $\mathrm{T}$ cells overcomes the suppressive effects of regulatory T cells via an IL-2 deprivation mechanism. Journal of Immunology 188: 800-810.

43. Berretta, F., J. St-Pierre, C.A. Piccirillo, and M.M. Stevenson. 2011. IL-2 contributes to maintaining a balance between CD4+Foxp3+ regulatory $\mathrm{T}$ cells and effector $\mathrm{CD} 4+\mathrm{T}$ cells required for immune control of blood-stage malaria infection. Journal of Immunology 186: $4862-4871$.

44. Zheng, S.G., J. Wang, and D.A. Horwitz. 2008. Foxp3+CD4+CD25+ regulatory T cells induced by IL-2 and TGF-beta are resistant to Th17 conversion by IL-6. Journal of Immunology 180: 7112-7116.
45. Todd, J.A., N.M. Walker, J.D. Cooper, D.J. Smyth, K. Downes, V. Plagnol, R. Bailey, S. Nejentsev, S.F. Field, F. Payne, et al. 2007. Robust associations of four new chromosome regions from genomewide analyses of type 1 diabetes. Nature Genetics 39: 857-864.

46. Yamanouchi, J., D. Rainbow, P. Serra, S. Howlett, K. Hunter, V.E. Garner, A. Gonzalez-Munoz, J. Clark, R. Veijola, R. Cubbon, et al. 2007. Interleukin-2 gene variation impairs regulatory $\mathrm{T}$ cell function and causes autoimmunity. Nature Genetics 39: 329-337.

47. Sgouroudis, E., A. Albanese, and C.A. Piccirillo. 2008. Impact of protective IL-2 allelic variants on CD4+Foxp3+ regulatory T cell function in situ and resistance to autoimmune diabetes in NOD mice. Journal of Immunology 181: 6283-6292.

48. Tang, Q., J.Y. Adams, C. Penaranda, K. Melli, E. Piaggio, E. Sgouroudis, C.A. Piccirillo, B.L. Salomon, and J.A. Bluestone. 2008. Central role of defective interleukin-2 production in the triggering of islet autoimmune destruction. Immunity 28: 687-697.

49. Tenorio, E.P., J. Fernandez, C. Castellanos, J.E. Olguín, and R. Saavedra. 2011. CD4+ Foxp3+ regulatory T cells mediate Toxoplasma gondii-induced T-cell suppression through an IL-2-related mechanism but independently of IL-10. European Journal of Immunology 41: 3529-3541.

50. Kryczek, I., S. Wei, L. Zou, S. Altuwaijri, W. Szeliga, J. Kolls, A. Chang, and W. Zou. 2007. Th17 and regulatory T cell dynamics and the regulation by IL-2 in the tumor microenvironment. Journal of Immunology 178: 6730-6733.

51. Zago, C.A., K.R. Bortoluci, L.R. Sardinha, F.D. Pretel, S.I. CastilloMéndez, A.P. Freitas do Rosário, M.I. Hiyane, S.M. Muxel, S.M. Rodriguez-Málaga, I.A. Abrahamsohn, J.M. Álvarez, and M.R. D'Império Lima. 2012. Anti-IL-2 treatment impairs the expansion of Treg cell population during acute malaria and enhances the Th1 cell response at the chronic disease. PLoS ONE 7: e29894

52. Dinh, T.N., T.S. Kyaw, P. Kanellakis, K. To, P. Tipping, B.H. Toh, A. Bobik, and A. Agrotis. 2012. Cytokine therapy with interleukin-2/ anti-interleukin-2 monoclonal antibody complexes expands CD4+CD25+Foxp3+ regulatory T cells and attenuates development and progression of atherosclerosis. Circulation 126: 1256-1266.

53. Andersen, M.H., J. Gehl, S. Reker, L.Ø. Pedersen, J.C. Becker, P. Geertsen, and P. thor Straten. 2003. Dynamic changes of specific T cell responses to melanoma correlate with IL-2 administration. Seminars in Cancer Biology 13: 449-459

54. Slingluff, C.L. Jr, G.R. Petroni, G.V. Yamshchikov, S. Hibbitts, W.W. Grosh, K.A. Chianese-Bullock, E.A. Bissonette, D.L. Barnd, D.H. Deacon, J.W. Patterson, J. Parekh, P.Y. Neese, E.M. Woodson, C.J. Wiernasz, and P. Merrill. 2004. Immunologic and clinical outcomes of vaccination with a multiepitope melanoma peptide vaccine plus interleukin-2 administered either concurrently or on a delayed schedule. Journal of Clinical Oncology 22: 4474-4485

55. Escobar, A., M. Lopez, A. Serrano, M. Ramirez, C. Pérez, A. Aguirre, R. González, J. Alfaro, M. Larrondo, M. Fodor, C. Ferrada, and F. Salazar-Onfray. 2005. Dendritic cell immunizations alone or combined with low doses of interleukin-2 induce specific immune responses in melanoma patients. Clinical and Experimental Iттиnology 142: 555-568.

56. Koreth, J., K. Matsuoka, H. Kim, S.M. McDonough, B. Bindra, E.P. Alyea 3rd, P. Armand, C. Cutler, V.T. Ho, N.S. Treister, D.C. Bienfang, S. Prasad, D. Tzachanis, R.M. Joyce, D.E. Avigan, J.H. Antin, J. Ritz, and R.J. Soiffer. 2011. Interleukin-2 and regulatory T cells in graft-versus-host disease. New England Journal of Medicine 365: 2055-2066.

57. Saadoun, D., M. Rosenzwajg, F. Joly, A. Six, F. Carrat, V. Thibault, D. Sene, P. Cacoub, and D. Klatzmann. 2011. Regulatory T-cell responses to low-dose interleukin-2 in HCV-induced vasculitis. New England Journal of Medicine 365: 2067-2077. 